\title{
HERMENÊUTICA JURÍDICA NO COMBATE À CRISE PREVIDENCIÁRIA
}

\author{
Eduardo Luís Zanchet ${ }^{1}$
}

\begin{abstract}
RESUMO: O presente artigo tratará de alguns aspectos da crise do sistema previdenciário pátrio, da evolução da Seguridade Social brasileira e do papel do operador jurídico no combate a esta problemática social. Procuraremos expor, de forma objetiva, causas da crise previdenciária e a necessidade do intérprete do direito atuar de maneira ativa e concatenada com fatos sociais.

PALAVRAS-CHAVE: Estado, Hermenêutica, Previdência
\end{abstract}

\section{Interpretation of Juridical phrases in the fight against the Social Security Crisis}

\begin{abstract}
The present article will treat some aspects of the national social security system, of the evolution of the Brasilian System and of the function of a judicial operator in combating this social problem. We seek to expose, in an objective form, causes of the Social Security crisis and a need of the interpretation of rights acting in a dynamic manner and connected to social facts.
\end{abstract}

KEY-WORDS: State, Interpretation, Foresight (Social Security)

\section{INTRODUÇÃO}

O objetivo do presente estudo é analisar alguns aspectos da tão comentada "crise" do sistema previdenciário e o papel do operador jurídico diante desta realidade social. Faremos uma acanhada tentativa de compreensão desta problemática que nos afeta - ou afetará - quotidianamente. Abordaremos, de maneira sintética, a evolução da seguridade social enquanto direito prestacional de segunda geração, bem como a necessidade de uma hermenêutica previdenciária própria, para que o intérprete do direito tenha instrumentos hábeis no combate à crise previdenciária.

Tal tema está umbilicalmente ligado às dificuldades de efetivação de direitos previdenciários básicos, garantidos constitucionalmente, ante uma sociedade marcada por desigualdades sociais e culturais gritantes. A concretização de direitos sociais ainda soa como algo demagógico, diante da total falência de um Estado do Bem-Estar Social tido, para muitos, como um "cadáver insepulto".

Faremos uma singela e inicial digressão a respeito dos elementos orgânicos do Estado e sobre sua finalidade precípua: instrumento de proteção social. Por derradeiro

\footnotetext{
${ }^{1}$ Acadêmico do $12^{\circ}$ Semestre de Direito da Universidade Federal de Santa Maria e Servidor do Instituto Nacional do Seguro Social - INSS.
} 
analisaremos o sistema securitário pátrio e o papel da hermenêutica jurídica na concretização destes direitos.

\section{Estado, Direito e Hermenêutica Jurídica}

O homem, desde os primórdios da civilização, obteve na necessidade do agrupamento social a forma de sobrevivência frente às intempéries do mundo. Nestes constantes embates, aqueles que possuíam uma autoridade central, que atuasse sobre as forças sociais ou os objetivos a conquistar seriam os aptos a sobreviverem. O ser humano, um “animal social”, possui uma natureza gregária por excelência. O Estado, portanto, surge a partir deste impulso associativo do homem, que, consciente ou inconscientemente, é levado a agrupar-se. Neste sentido esclarece Rizzardo (2004):

O homem é um ser eminentemente social. Ninguém vive isolado, A realização humana é atingida progressivamente pela expansão do relacionamento social. Pessoa alguma suporta a vida isolada. Basicamente, passa-se a vida em função dos outros (...) Na medida em que se aperfeiçoaram ou se aculturaram as civilizações, mais se desenvolveram as regras de condutas sociais. (RIZZARDO, 2004, p.01)

Da evolução, lenta e gradual, deste modelo de coexistência social extrai-se os três conhecidos elementos básicos do Estado: Povo - Elemento orgânico do Estado; Território local sobre o qual se irradia a soberania estatal e, por fim, Governo - definido sinteticamente como o poder soberano que garante a unidade deste corpo social ${ }^{2}$, tendo por características a supremacia na ordem interna e a independência internacional.

O homem, como visto, encontrou na coexistência a forma de sobrevivência diante das intempéries naturais e sociais. Deste agrupamento, porém, surgem variados e complexos problemas sociais, mazelas capazes de fazê-lo retornar ao seu estado natural de beligerância. Faz-se necessário que o Estado encontre meios de proteção social. Surge, então, o direito. Estes mecanismos foram dissecados por várias teorias - inclusive antagônicas - a respeito da origem do Poder Estatal e Contratualismo Social. Citamos, a título exemplificativo, Hobbes, Locke, Maquiavel, Grotius e Rousseau.

\footnotetext{
${ }^{2}$ Segundo Jean Bodin (1576): “A república, sem a potência soberana que una todos os membros e partes, e todas as famílias e colégios, num só corpo, já não é mais república. Não há comunidade sem unificação.” (Jean Bodin. Os Seis Livros da República- 1576)
} 
Direito, definido de maneira livre, como um sistema de normas, organizadas sob a égide de um ordenamento jurídico, é, antes de tudo, uma manifestação de Poder Soberano. Poder, esclarece Gérard Lebrun, na teoria da "Soma Zero"3", é a potência, determinada por certa força, que se explicita de maneira precisa através de uma ordem. O poder, quando transmitido por alguém - e obedecido por outros - forma a autoridade. Aquilo que conhecemos como "Poder Soberano", tecnicamente, não é poder, mas autoridade soberana que, em um Estado Democrático de Direito, é a representação da vontade popular acrescida de respeito a direitos fundamentais constitucionalmente garantidos.

O Direito, por sua vez, é o instrumento mais eficaz para a manifestação do poder estatal pela autoridade soberana. Este, como produto da cultura humana, é um dos meios de resolução de conflitos existentes no Estado. No inicio das civilizações era confundido com religião e moral, adquirindo feições místicas a serem respeitadas. O Direito, até o final da Idade Média, tinha por objetivo primordial manter o grupo coeso. O ideal latente de justiça social, intimamente ligado ao direito moderno, tinha, naquela época um viés secundário.

O Estado Democrático de Direito é fruto, por óbvio, desta evolução histórica: perpassou por "etapas" tirânicas, absolutistas, pela própria negação do Estado frente ao fenômeno do liberalismo. As barbáries da Segunda Grande Guerra Mundial orientaram o Estado Democrático de Direito como aquele submetido às próprias normas e à Constituição e elencaram a dignidade da pessoa humana como norma informadora de todo o direito.

Neste modelo estatal, como o nome já aponta, o Estado está submetido ao Direito e à Constituição. Esta forma de Estado material, e não apenas formalmente criado, é aquela que começa a existir a partir da garantia dos direitos fundamentais, dentre eles a garantia à Seguridade Social. Tem-se por finalidade a garantia de que os cidadãos não serão atingidos por políticas oriundas de favoritismos, perseguições, humores, meros caprichos ou finalidades quaisquer que não a busca pelo bem comum, pelo interesse público.

No que tange à hermenêutica, o vocábulo é derivado do grego hermeneuein, a palavra está ligada a Hermes, o deus intérprete da mitologia grega, entidade sobrenatural dotada de capacidade de traduzir, decifrar o incompreensível. Parte da doutrina distingue

\footnotetext{
${ }^{3}$ Segundo a teoria do "poder de soma zero": Se X tem poder, é preciso que em algum lugar haja um ou vários Y que sejam desprovidos de tal poder. Segundo este filósofo parisiense, nenhuma organização política moderna poderia funcionar sem dominação e que o único problema político é, então, saber qual o melhor modo de determinar e adequar esta dominação em função de valores e escala de valores escolhidos.
} 
"hermenêutica" e "interpretação"; aquela seria a teoria científica da arte de interpretar; esta seria a aplicação da hermenêutica; em suma, a hermenêutica seria teórica e a interpretação seria de cunho prático, aplicando os ensinamentos da hermenêutica.

Outra parte da doutrina, a quem seguimos, entende que hermenêutica jurídica é a arte de interpretar, aplicar e integrar o direito. É um processo, portanto, constante de construção e re-construção, não é uma relação meramente contemplativa, onde a interpretação jurídica se apresenta como verdade absoluta. A abordagem de uma hermenêutica atual não se resume na interpretação da norma, mas em um processo constante de criação. Pensar no direito como um sistema napoleônico fechado é inconcebível, frente aos mais variados fatos sociais.

No direito securitário, há a necessidade de criação de uma hermenêutica previdenciária própria, não levando em consideração apenas o campo abstrato da lei, mas também o campo concreto e real dos fatos. Principalmente na análise das peculiaridades dos segurados do Regime Geral de Previdência Social (Pessoas que, não raras às vezes, encontram-se totalmente desprovidas de qualquer proteção jurídica, econômica, cultural) e, também, na necessidade de manter um equilíbrio financeiro e atuarial do sistema previdenciário, visando a futura e salutar aplicação das verbas destinadas à proteção social.

\section{Evolução da Seguridade Social}

A seguridade social é definida, no artigo 194 da Constituição Federal, como um conjunto integrado de ações de iniciativas dos Poderes Públicos e da sociedade, destinadas a assegurar os direitos relativos à saúde, previdência e assistência social. Este sistema securitário, como regime protetivo, surgiu a partir das lutas dos trabalhadores por melhores condições de vida.

O Estado Contemporâneo, como visto, possui, a função precípua da proteção social dos indivíduos. No que tange a seguridade social, a proteção dá-se em relação a eventos que lhe possam causar a dificuldade ou a impossibilidade de subsistência. Segundo os eminentes autores Carlos Alberto Pereira de Castro e João Batista Lazzari, até o Século XVIII não havia a sistematização de qualquer forma de prestação estatal no que tange à 
seguridade social. Qualquer forma de proteção anterior a este período tinha características eminentemente mutualista, voltada ao auxílio recíproco de seus membros.

Sob a ótica previdenciária, o marco embrionário da seguridade social foi $o$ ordenamento legal editado na Alemanha, por Otto Von Bismarck, em 1883, que instituiu o seguro doença e o auxílio acidente. Neste sistema de capitalização pagava-se única e exclusivamente para si, faltava-lhe, portanto, a noção de solidariedade social.

A primeira constituição a tratar, efetivamente, do tema seguridade social foi a Constituição Mexicana de 1917, seguida pela Constituição de Weimar de 1919. Nos Estados Unidos, em 1935 foi editada, no período pós-depressão, a "Social Security Act", criando a previdência como forma de proteção social e garantia de direitos fundamentais. A evolução da seguridade social teve, porém, como ponto dominante o chamado "Plano Beveridge”, idealizado na Inglaterra pelo Lord Willian Henry Beveridge que, utilizando as idéias de redistribuição de renda de John Maynard Kynes, criou um sistema de repartição simples, semelhante aos regimes previdenciários atuais.

A doutrina majoritária estabelece como marco da Previdência Social no Brasil a Lei Eloy Chaves - Decreto Legislativo 4.682 de 24 de Janeiro de 1923. Esta criou um sistema previdenciário para os trabalhadores ferroviários com prestações de aposentadoria por invalidez, pensão por morte, aposentadoria ordinária ou por tempo de serviço e assistência médica.

A seguridade social, como forma de proteção social, segundo o conceito ditado pela ordem jurídica vigente, é composta por três subsistemas: saúde, assistência e previdência social. Valores estes que, se vislumbrados sob a sistemática da seguridade social, ultrapassam o arcaico conceito de um simples seguro administrado pelo Estado e garantem o atendimento das ambiciosas diretrizes constitucionais a respeito da matéria.

Um destes subsistemas é a Previdência Social. Os artigos 201 e 202 da Constituição Federal tipificam que a previdência social será organizada sob a forma de regime geral, de caráter contributivo e filiação obrigatória, tendo por fim assegurar aos seus beneficiários meios indispensáveis de manutenção, por motivo de incapacidade, desemprego involuntário, morte, idade avançada, maternidade e outros riscos sociais capazes de retirar a manutenção do sustento. Esclarece Leira (2001): 
A partir da Constituição de 1988, a Previdência Social é parte do conjunto integrado de ações destinadas a assegurar os direitos aos trabalhadores quando não mais podem prover o seu sustento, seja temporária, seja definitivamente, quer pela incapacidade temporária ou permanente, quer pela idade ou fator tempo de serviço efetivado. (LEIRA, 2001, p. 127)

Partindo de uma concepção analítica do artigo 201 da Constituição Federal, previdência social poderia ser definida como um dos ramos da seguridade social que, organizada sob a forma de um regime jurídico-previdenciário, de caráter contributivo e filiação obrigatória, atenderá riscos sociais previamente definidos como, por exemplo, cobertura de eventos como doença, invalidez, morte, idade avançada; proteção à maternidade; proteção ao trabalhador em situação de desemprego involuntário; proteção à família de dependentes de baixa renda.

Sob o enfoque material, Previdência Social é um direito social subjetivo do indivíduo, exercido frente ao Estado-Providência, já que a sociedade e, consequentemente, este indivíduo, através de um sistema de custeio do seguro social, garantiu os recursos financeiros suficientes para a aplicação da política de segurança social.

José Afonso da Silva (2005), ao tratar da seguridade social, a define como importante instrumento no que tange a ordem social e elenca uma série de princípios, além daqueles presentes no artigo 194 da Magna Carta de 1988, vislumbrados a partir de um enfoque doutrinário da matéria:

A seguridade social constitui um instrumento mais eficiente da liberação das necessidades sociais, para garantir o bem estar material, moral e espiritual de todos os indivíduos da população, devendo repousar nos seguintes princípios: a) universalidade subjetiva (não só para os trabalhadores e seus dependentes, mas para todos, indistintamente); b) universalidade objetiva (não só reparadora, mas preventiva do surgimento da necessidade, protetora de qualquer circunstância); c) igualdade protetora (prestações idênticas em função das mesmas necessidades; não distinta como na Previdência em função da quantidade de contribuição); d) unidade de gestão (só é administrada e outorgada pelo Estado); e) Solidariedade financeira (os meios financeiros procedem de contribuições gerais, não de contribuições específicas dos segurados). (SILVA, 2005, p.759) 


\section{Alguns Aspectos da "Crise" Brasileira e O Papel do Operador Jurídico}

Durante todo período do Estado liberal, pós-absolutista, que manteve seu apogeu desde a Revolução Francesa até o inicio do século XX, não há que se falar em sistema previdenciário obrigatório. Neste modelo laissez faire, laissez passer, o Estado possuía uma nítida função abstencionista, seu papel precípuo era assegurar a total liberdade entre os cidadãos, não havendo espaço para condutas protetivas aos hipossuficientes.

Com a evolução da civilização, durante a Era Contemporânea, porém, concretizamse direitos sociais (de Segunda Geração). Passou a ser admitida a interferência da autoridade estatal na esfera jurídica privada, permitindo-se cobranças compulsórias, vertidas a um sistema previdenciário estatal, tendo por finalidade o interesse social e a proteção jurídica daqueles que, por algum evento futuro, encontrar-se-iam em uma situação de risco social.

A evolução do sistema previdenciário mundial alcançou seu ápice, conforme visto no capítulo supra, com o Plano Beveridge. Esta política previdenciária inglesa criou um sistema de repartição simples, contrapondo-se ao clássico sistema de capitalização bismarckiano, em que cada pessoa contribui para si, formando uma espécie de fundo individual de previdência. Naquele sistema de repartição simples, todavia, os ativos, através de contribuições a um regime securitário, sustentam os inativos, tendo em vista que os contribuintes de hoje serão, baseado em um juízo de previsibilidade, mantidos pelo sistema no futuro.

O sistema de repartição simples foi o regime previdenciário dominante na maioria dos países, provavelmente pelo fato de possuir uma índole protetiva em que a solidariedade e previsibilidade lhe são inerentes, conceitos estes que são as "pedras de toque" de qualquer sistema securitário. Devido a vários fatores, contudo, esta forma de repartição previdenciária encontra-se em crise: o número de inativos cresce diuturnamente, enquanto os recursos tornam-se cada vez mais escassos.

Abordaremos, nesta singela explanação, o Regime Geral de Previdência mantido pela autarquia federal INSS, visto que este é o mais complexo e abrangente regime securitário. Muitos de seus aspectos, porém, podem ser, resguardadas as peculiaridades de cada caso, aplicados aos Regimes Próprios de Previdência Social. 
No Brasil fala-se da "crise previdenciária" há décadas. As cifras, acompanhadas de demonstrações fáticas, nos dão o panorama de que a Previdência Social brasileira apresenta dificuldades financeiras no combate à crise ${ }^{4}$. A opinião pública, porém, ainda diverge sobre a existência de uma crise na Previdência Social.

Para alguns não há crise financeira na Previdência Social. Os números utilizados para avaliar a situação financeira da Previdência são alarmistas, resultado, muitas vezes, de interesses de particulares e fundos de pensão que almejam desestabilizar a Previdência Social, visando aumentar seus lucros. Estudos realizados pela professora do Instituto de Economia da UFRJ Denise Gentil, demonstram que o cálculo do que é divulgado como déficit não leva em consideração todas as receitas que devem ser alocadas para a Previdência Social, de acordo com a Constituição Federal de 1988. "Deixa-se de computar recursos significativos provenientes da COFINS, CSLL e receita de concursos de prognóstico 5 ."

É inegável, todavia, que a opinião pública tem voltado seus olhos para uma perspectiva cada vez mais crítica quanto à forma como serão pagos os benefícios para as gerações que estão ingressando nos diversos Regimes de Previdência, bem como para aquelas que ainda não preencheram os requisitos para concessão dos benefícios. Paulo César de Souza, Presidente da Associação Nacional dos Servidores da Previdência Social, elenca causas clássicas na crise estrutural da previdência. São elas: desequilíbrio econômico-financeiro, resultado no mau ou péssimo gerenciamento da Previdência, especialmente de 1994 para cá, tanto no INSS como nos fundos de pensão; desequilíbrio atuarial, cada dia menos ativos contribuem para o financiamento e a manutenção dos inativos; desequilíbrio demográfico, com a melhoria da qualidade de vida, a expectativa de

\footnotetext{
4 “ $\mathrm{Na}$ década de 50 oito contribuintes financiavam cada beneficiário. Em 1970, essa relação era de 4,2 para 1; o número de contribuintes por beneficiário foi decrescendo: 2,8, em 1980; 1,9, em 1995. Esta relação tem que ver, naturalmente, com o tempo que os segurados, em média, contribuem para o sistema e, depois, percebem benefícios cuja a finalidade é a substituição do salário. Estima-se que, se as regras de concessão de aposentadoria fossem mantidas, a expectativa seria de que, em 2030, cada contribuinte teria que sustentar um beneficiário." (CASTRO, Carlos Alberto Pereira de; LAZZARI, João Batista. Manual de Direito Previdenciário, Editora Conceito, $9^{a}$ Edição, Florianópolis: 2008. página 681)

5 "Se computada a totalidade das fontes de recursos que cabem à Previdência conforme disposto na Carta Magna e deduzida a despesa total, inclusive com pessoal, custeio, dívida do setor e gastos nãoprevidenciários, o resultado apurado será um superávit de R\$ 921 milhões em 2005 e de R\$1,2 bilhão em 2006." http://webmail.andes.org.br/modules/smartsection/item.php?itemid=106 (acesso em 20/04/2009)
} 
vida se ampliou o que alonga o tempo de duração do benefício; desequilíbrio patrimonial, de 1994 para cá, cresceram "desmedidamente" as renúncias contributivas (R $\$ 10$ bilhões) sobre a Previdência, o estoque da dívida (R 150 bilhões), ampliaram-se os favorecimentos através do Simples e do Refis, a corrupção, malversação, evasão, sonegação, elisão e fraudes chegam a $40 \%$ da receita ${ }^{6}$.

Vez por outra, como visto, aborda-se o déficit da previdência, e os mais diversos setores da sociedade são chamados a dar seus “pareceres”. Discursos, muitas vezes, eivados de cargas ideológicas, jogam-se com dados dúbios. Tudo acaba por gerar reformas legislativas desmedidas, o que causará, consequentemente, insegurança jurídica: problemática que desaguará em uma incessante busca pela prestação jurisdicional. Instaurase a "correria" em busca do benefício previdenciário, tudo em meio ao caos normativo e jurisprudencial e, como afirma com maestria Moacir Camargo Baggio, "em meio a essa borrasca que se encontra atualmente o Direito Previdenciário. Como um barco à deriva, é empurrado sem rumo, fortemente sacudido pelos violentos ventos e pelas perigosas vagas desse turbilhão de modernidade". ${ }^{7}$

Cumpre-se ressaltar que a situação da maioria dos Regimes Próprios de Previdência Social, ou seja, aqueles formados por agentes ocupantes de cargos públicos da Administração Direta, das autarquias e fundações também é crítica. Não há, em muitos destes regimes, o controle para manter o necessário equilíbrio financeiro e atuarial. Neste sentido, argumenta, com propriedade, Stephanes (1998):

$\mathrm{O}$ aumento dos gastos com o pagamento do pessoal ativo e inativo aponta para a insolvência da maioria dos tesouros estaduais no (sic) curto prazo. Tais despesas reduzem o espaço para os investimentos necessários em infra-estrutura, saneamento básico, educação, saúde, habitação e segurança. E se os governos mantivessem a política de reajustes dos salários do funcionalismo, interrompida a mais de três anos, esse quadro poderia ter tomado proporções ainda mais recessivas. Assim, o ajuste dos regimes vem ocorrendo de forma mais traumática para seus contribuintes. (STEPHANES, 1998, p. 105)

\footnotetext{
${ }^{6} \mathrm{http}: / /$ www.midiaindependente.org/pt/blue/2003/05/255545.shtml. (acesso em 09/05/2009).

${ }^{7}$ LUGON, Luiz Carlos de Castro; LAZZARI, João Batista. (Org) Curso Modular de Direito Previdenciário, Editora Conceito, Florianopólis: 2007. p. 172.
} 
Os dados supra mencionados devem ser analisados com cautela pelo operador jurídico. A Previdência Social, inegavelmente, apresenta problemas de ordem estrutural e financeira que exigem do intérprete do direito, inicialmente, a exata compreensão. A constante evolução da biomedicina, por exemplo, fez aumentar a faixa etária populacional, causando, como consequência, o aumento da expectativa de vida da população. Para tais fatos não houve um adequado estudo sobre a matéria. Neste ponto, ressalta Dowbor (1997):

O segmento que mais aumentou os gastos do Estado é o das aposentadorias, e resulta simplesmente do aumento do tempo de vida do ser humano e da mudança da pirâmide etária. Grande parte do que nos apresenta como o odioso gigante estatal resulta do fato de que, como sociedade, temos que sustentar uma juventude que estuda mais tempo, e idosos que vivem mais tempo. O novo equilíbrio social entre ativos e inativos é simplesmente uma questão de custo para a sociedade, que resulta de uma evolução positiva. Culpar o Estado representa uma solene bobagem, que só adquire respeitabilidade nos meios de comunicação pelo interesse natural dos grupos financeiros privados de se apropriarem de mais esta fatia de intermediação. (DOWBOR, 1997, p. 361)

Há que se observar, ainda, que na atual estrutura social pátria, milhares de trabalhadores ainda se mantém na informalidade, não vertendo qualquer espécie de contribuição ao sistema. Tais pessoas, por falta de qualificação profissional, não encontram um aporte financeiro sustentável que lhes permite verter contribuições à Previdência Social. Como consequência, necessitarão, inevitavelmente, ser amparados por políticas de assistência social. O que representará maiores gastos para o Estado, bastando mensurar que os subsistemas Previdência e Assistência englobam a Seguridade Social. O Estado, enquanto administrador dos Direitos Sociais, deveria trabalhar de forma eficaz com o estímulo ao trabalho, através de políticas preventivas de incapacidade, desemprego e, principalmente, valorização do emprego na terceira idade.

A má gestão dos recursos é outro fator desencadeante e fomentador da crise. Observa João Batista Lazzari que durante muitos anos o regime serviu para custear não os benefícios ou formar fundos de reserva, mas para construir obras públicas faraônicas. Soma-se a isso: a falta de controle na concessão dos benefícios e a ineficácia na cobrança dos grandes devedores. É fato que o governo não tem estrutura para fiscalizar a formalização do trabalho e controlar as contribuições sociais obrigatórias; a má gestão profissional, em que os cargos de direção ainda são objetos de barganha política (basta 
observar os escândalos causados por fraudes previdenciárias); uma legislação mal formulada, em que muitos benefícios são concedidos com privilégios, desrespeitando a regra constitucional, tipificada no artigo $195 \$ 5^{\circ}$ da Magna Carta, que prevê o equilíbrio financeiro e atuarial para a concessão de benefícios.São estes alguns aspectos que o operador do direito, administrador de situações conflituosas, deve observar para contribuir no combate à crise previdenciária.

Há que se distinguir, para a exata compreensão da matéria, os conceitos "crise" e "déficit". Este é, apenas, um dos aspectos daquela. O déficit financeiro é, sem dúvidas, o elemento mais complexo e significativo da crise previdenciária, mas não é o único. Um sistema previdenciário financeiramente equilibrado, por exemplo, estará em crise caso não cumpra, de maneira eficaz, o fim para o qual se destina, qual seja: a regular concessão e manutenção dos benefícios previdenciários. A função da Previdência Social não é ser superavitária, mas, isto sim, preservar o equilíbrio financeiro e atuarial para garantir os propósitos constitucionais a que se destina. O fim de todo o sistema securitário é coincidente, por óbvio, com a finalidade da Administração Pública: a satisfação concreta dos interesses coletivos.

O papel do juiz, enquanto operador jurídico, é preservar de maneira salutar este binômio, ou seja, concretizar os direitos sociais, através da aplicação efetiva do direito previdenciário, levando em consideração a realidade fática de cada segurado, sujeito hipossuficiente na relação jurídica, carecedor da função protetiva do Estado. Não poderá, contudo, esquecer do dever preservar o equilíbrio financeiro do sistema, já que Previdência Social pressupõe, necessariamente, contribuição. Neste ponto, professora, com a habitual clareza que lhe é peculiar, Leira (2001):

No cotejo dos dispositivos legais, com as dificuldades da prova do efetivo trabalho prestado, também nunca pode o julgador perder de vista a possibilidade de fraudes, que resultariam na falência do sistema previdenciário. De outro lado, vislumbramse as dificuldades enfrentadas pelo trabalhador do campo que, muitas vezes, longe dos centros populacionais, não guardou qualquer prova escrita de sua vida laboral. Por isso o exame atento de cada caso. Em alguns, há as certidões de casamento nas quais está registrada a profissão do trabalhador (prova escrita da época); em outros, há o bloco de produtor rural; em outros, a residência, o lugar de nascimento, a relação com o dono da terra (...). Tudo isso serve como o início de prova material exigido na LBPS, em seu artigo $55, \S 3^{\circ}$, para fins de comprovação de tempo de serviço (LEIRA, 2001, p. 149). 
Ao construir a hermenêutica previdenciária, o juiz deve ter presente o respeito ao Estado Democrático de Direito, aos princípios constitucionais, às instituições e, sobretudo, à dignidade da pessoa humana, decidindo de acordo com valores de justiça social, não sendo um mero reprodutor da letra fria da lei, apegado ao puro formalismo. Não poderá, também, deixar-se "seduzir pelo canto das sereias", tendo uma visão totalmente liberal e desapegada, já que é mais fácil (e cômodo) conceder um benefício, mesmo que precoce e amparado em tempos de serviço fictícios, pois esta posição, não raras vezes, apresenta uma falsa conotação de "fazer justiça".

O operador jurídico deverá, após a análise do caso concreto, ponderar entre o necessário ativismo judicial, postura ativa do Poder Judiciário na implementação e concretização de direitos sociais frente à sabida omissão dos poderes públicos; e o respeito ao mecanismo da separação dos poderes, sob pena de instaurar-se uma "ditadura togada". Neste sentido, reproduzimos, por derradeiro, as sábias palavras do Juiz Federal Zenildo Bodnar (2007):

Alguns magistrados mais sensíveis concedem benefícios apenas com base no 'princípio do tadinho', Outros, porém, sentem-se os 'donos do cofre' e acreditam que eventual flexibilização de alguns rigores da norma, ainda que seja para atender aquelas situações de extremada gravidade, levarão necessariamente o sistema ao colapso por falta de recursos. Há também a manipulação inadequada do princípio do retrocesso, os quais podem servir de 'falso fundamento', tanto para negar quanto para reconhecer direitos previdenciários e sociais. Esta falta de critérios racionais nas decisões gera insegurança jurídica e multiplicação de demandas por falsas e ilusórias expectativas criadas para a população (LUGON. LAZZARI- Org. 2007, p. 19).

\section{CONSIDERAÇÕES FINAIS}

O operador jurídico é, antes de tudo, um administrador de situações conflituosas. Árdua é sua tarefa na concretização de direitos sociais, constitucionalmente garantidos, frente à omissão dos Poderes Públicos. Essa inércia é constantemente observada justamente onde o Estado teria o dever - positivo - de agir: nos direitos de segunda geração.

A solução da crise previdenciária, tema complexo tendo em vista o "jogo de interesses" e o rol de direitos sociais em voga, exige do intérprete-aplicador do direito uma 
conduta ativa. Deverá partir, por óbvio, da exata compreensão do problema para, posteriormente, agir na aplicação do direito, mais um dos elementos necessários no combate à crise securitária. Deverá, na luta pela pacificação social, construir uma hermenêutica previdenciária própria, com técnicas de interpretação e aplicação que coadunem, mediante precisão cirúrgica, os direitos sociais em conflito com a salutar manutenção do regime securitário.

A hermenêutica própria é o meio capaz de proporcionar coerência a todo o sistema previdenciário, evitando que o mesmo seja usurpado, utilizado como instrumento de desigualdade, frente a uma sociedade já desigual. Aplicar o direito previdenciário é uma tarefa árdua para o operador jurídico. É garantir a concretização de direitos sociais indispensáveis à mantença da dignidade da pessoa humana. Jamais poderá ser tratado como um labor jurídico descompromissado, em que se joga com vidas ou, em situação diametralmente oposta, representar um ato de rebeldia contra o Estado, como se este fosse o único responsável por todas as mazelas sociais existentes.

\section{REFERÊNCIAS BIBLIOGRÁFICAS}

BOBBIO, Norberto. A Era dos Direitos. Editora Campus, $3^{\text {a }}$ Edição. Rio de Janeiro: 2004.

CASTRO, Carlos Alberto Pereira de; LAZZARI, João Batista. Manual de Direito Previdenciário, Editora Conceito, 9ª Edição, Florianópolis: 2008.

DOWBOR, Ladislau. "Globalização e Tendências Institucionais". Desafios da Globalização. Petrópolis: Editora Vozes, 1997

GORCZEVSKI, Clóvis. Direitos Humanos. A segunda geração em debate. Editora

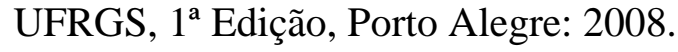

KertZMAn, Ivan. Curso Prático de Direito Previdenciário, Editora JusPodivm, $4^{\text {a }}$ Edição, Salvador: 2005. 
LEBRUN, Gerard. O que é poder, Editora Brasiliense, 14ª Edição, São Paulo: 2004,

LEIRA, Maria Lúcia Luz. Direito Previdenciário e Estado Democrático de Direito: uma (re)discussão à luz da hermenêutica, Livraria do Advogado, Porto Alegre: 2001.

LUGON, Luiz Carlos de Castro; LAZZARI, João Batista. Curso Modular de Direito Previdenciário, Editora Conceito, Florianopólis: 2007.

MARTINS, Sérgio Pinto. Direito da Seguridade Social, Editora Atlas, $19^{a}$ Edição, São Paulo: 2003.

RIZZARDO, Arnaldo. Direito das Obrigações, Editora Forense, $2^{\mathrm{a}}$ edição, Rio de Janeiro:2004.

SANTOS, Marcos André Couto. O direito como meio de pacificação social: em busca do equilíbrio das relações sociais. Revista da Procuradoria Geral do INSS. Brasília, vol. 7, N- 4, 77-88, jan/mar, 2001.

SILVA, José Afonso da. Comentário Contextual à Constituição, Editora Malheiros, $1^{\text {a }}$ Edição, São Paulo: 2005.

STEPHANES, Reinhold. A Reforma da Previdência sem segredos. Editora Record, Rio de Janeiro: 1998. 